\title{
Emotional Intelligence, Coping and Psychological Distress: A Partial Least Squares Approach to Developing a Predictive Model.
}

\author{
Alistair Campbell (Alistair.Campbell@jcu.edu.au) \\ School of Psychology \\ James Cook University, Townsville, Australia \\ Alice Ntobedzi \\ School of Psychology \\ James Cook University, Townsville, Australia
}

\begin{abstract}
Partial Least Squares analysis is an alternative way of modeling data which is relatively new to the Social Sciences. The current study, reported here, investigated the relationship between emotional intelligence, coping styles and the experience of psychological distress in adolescents. Although there has been quite a lot of research in this area there are few predictive models in the literature relating to adolescents. Participants were 85 Australian high school students. It was predicted that higher emotional intelligence would be related to decreased levels of psychological distress and to more adaptive coping but to less maladaptive coping. The results showed no direct association between emotional intelligence and psychological distress. However, there appeared to be an indirect relationship with psychological distress being predicted by coping style and coping style predicted by emotional intelligence. The implications of these findings for interventions with adolescents are discussed.
\end{abstract}

Keywords: Emotional Intelligence, Coping, Distress, Partial Least Squares

\section{Introduction}

The purpose of this study was to investigate the relationship between emotional intelligence and ways of coping in adolescents. The theory of emotional intelligence proposes that individuals have the ability to perceive, express, understand, and manage emotions (Bar-On, 1997; Goleman, 1995; Mayer \& Salovey, 1997; Salovey \& Mayer, 1990). Ciarrochi, Chan, Caputi and Roberts (2001) and Taylor (2001) hypothesised that individuals high in emotional intelligence may adapt well to stressful events and those with low emotional intelligence may adapt poorly, which would include responding with depression, hopelessness, and other negative behaviours. However, little empirical research has explored the relationships between emotional intelligence, coping and mental health in adolescents (Taylor, 2001). In addition, the concept of emotional intelligence has been related to healthy coping strategies (Jordan \& Troth, 2002). However, little is known about whether emotional intelligence can predict the use of healthier and more adaptive coping strategies in adolescents.
In addition to emotional intelligence, evidence suggests that coping may be related to other emotional competencies, such as self-monitoring, self-control, and empathy (Davis, 1980; Lennox \& Wolfe, 1984). This set of competencies, which deal with the recognition and regulation of moods and emotions, have been shown to relate to psychological health, at least in adults (Lennox \& Wolfe, 1984; Rohde, Lewinsohn, Tilson, \& Seeley., 1990). The current study undertook an exploration of the variables, emotional intelligence, coping, and emotional competencies, and their interrelatedness in adolescents as they seem to be especially relevant to this population and form the basis for strength based interventions.

\section{Coping with Stressful Situations in Adolescents}

Adolescence is a particularly difficult time and teenagers undergo many rites of passage, as well as having to deal with the usual problems of living in a family and being at school (Moulds, 2003; Rigby \& Cox, 1996). They must be flexible and frequently have to adapt to difficult situations. Coping with stressful situations has been identified as an important protective factor at a personal level.

Coping resources during adolescence include those aspects of the self (e.g., problem solving skills, interpersonal skills) and the social environment (e.g., the availability of supportive social network) that facilitate or make possible successful adaptation to life stress (Compas, 1987). Adequate coping during adolescence predicts good future outcomes, including higher levels of ego development, fewer behavioural problems, higher self-esteem, lower levels of depressive symptoms, and positive adjustment (Mullis \& Chapman, 2000; Printz, Shermis, \& Webb, 1999; Recklitis \& Noam, 1999; Seiffge-Drenke \& Klessinger, 2000). Evidence shows that well-adjusted adolescents use more mature coping strategies than those who are poorly adjusted (Tolor \& Fehon, 1987).

The cognitive transitions in adolescence have important implications for psychological development of young people. There is evidence that cognitive processes are crucial for the acquisition of emotionfocused coping skills. These are strategies that involve 
internal processes of cognitive and emotional selfcontrol, such as avoidance, minimisation, distancing, selective attention, positive comparisons, and finding positive value from negative events (Lazarus \& Folkman, 1984).

\section{Emotional Intelligence and Coping with Stressful Situations}

The process of coping includes ways in which an individual manages emotions, thinks constructively, regulates and directs behaviour, controls autonomic arousal, and acts on the social and non-social environments to alter or decrease sources of stress (Compas et al., 2001; Lazarus \& Folkman, 1984; Mayer \& Salovey, 1997). Managing the emotional experiences resulting from stressful situations is crucial for adaptive coping (Lazarus \& Folkman, 1984; Mayer \& Salovey, 1997). The theory of emotional intelligence provides a framework for understanding individual differences in managing and regulating emotions. According to the framework of emotional intelligence, one must be competent at understanding one's emotions (including negative emotions) to be able to process emotional information accurately and efficiently, and must have the insight to skilfully use emotions and manage them (Mayer \& Salovey, 1997).

Mayer and Salovey have argued that an individual with emotional intelligence "can be thought of as having attained at least a limited form of positive mental health". These individuals are considered to be well adjusted and emotionally skilled. These individuals are often aware of their emotions as they experience them, and this awareness can facilitate effective mood regulation, which in turn contributes to well-being (Mayer \& Salovey, 1990). Furthermore, the skills of regulating or controlling emotions and their expression could be associated with increased capacity for coping, as these regulatory processes can facilitate reduction of the frequency, intensity, and duration of distressing states (Mayer \& Salovey, 1997).

There is some preliminary evidence to suggest some forms of emotional intelligence may protect people from stress and lead to better adaptation. For example, emotional intelligence is positively associated with skill at identifying emotional expressions and it is positively associated with mood management (Ciarrochi, Chan \& Caputi, 2000). Other research has suggested that emotional intelligence is related to coping. Components of emotional intelligence, including social skills and managing emotions were found to be related to coping strategies, such as social support and involvement in activities in adolescents (Ciarrochi, Chan, \& Bajgar, 2001; Swiatek, 1995, 2001). This evidence suggests that individuals high in emotional intelligence would be expected to have greater ability to plan and decide on coping resources that reduce harmful effects of stress.
Conversely, individuals with deficits in emotional intelligence are considered to be impaired in emotional and social functioning (Salovey \& Mayer, 1990). Maladaptive dimensions of coping are often associated with the risk of onset of psychological disorders, such as antisocial behaviour, illegal substance use, depression and eating disorders (Rutter \& Smith, 1995). Researchers have suggested that deficiencies in managing emotions appropriately are related to involvement in risk taking behaviours (e.g., Compass et al., 2001; Goleman, 1995). Furthermore, low emotional intelligence has been correlated with excess amounts of alcohol consumption, tobacco use, illegal drug use, and involvement in deviant behaviour (Brackett, Mayer, \& Warner, 2004; Trinidad \& Johnson, 2001).

\section{Constructs of Emotional Competence}

A number of other constructs have been described which are aspects of social and emotional competence but not necessarily part of the Emotional Intelligence construct. Many of these constructs have been connected with stress and coping. For instance, selfawareness or self-monitoring competencies are relevant in the context of coping and regulation of negative emotions (Lennox \& Wolfe, 1984; Mayer \& Salovey, 1997). Mayer and Salovey argued that the ability to understand emotions forms the basic skill of emotional intelligence. People with heightened self-awareness know which emotions they are feeling, can name and label them, and can realise the chain from emotion to action (i.e., the links between their feelings, what they think and what they do). Self control has also been associated with social competence, adjustment and risk taking behaviours (Barkley, 1997; Strayhorn, 2002). Empathy, or the ability to understand the emotions of others (Davis, 1980; Mayer \& Salovey, 1997), has been linked to emotional intelligence (Salovey \& Mayer, 1990) and has also been considered as a basis for coping with stress (Goleman, 1995).

\section{Summary}

In summary, emotional intelligence begins with the capacity for recognising own and other's emotions, and with such heightened awareness, one then brings into play the abilities for managing emotions. Those who use emotional intelligence to guide their thoughts and actions may find it easier to adjust to stressful life events. Therefore, these individuals may be expected to have increased self-control skills, empathetic skills, self-awareness, to be more likely to engage in adaptive coping strategies, and in turn report reduced levels of psychological distress. However, there are few studies relating to adolescents which have modeled the 
relationships between the multitude of variables that have been identified as relevant.

The principal aim of this study was to develop a model of the relationships between emotional intelligence and ways of coping in adolescents. Accordingly, the present study investigated; (i) the extent to which adolescents use adaptive coping strategies (e.g., stoicism, social support, and self-care) and maladaptive coping strategies (e.g., acting out, rumination) using the MACS (Sveinbjornsdottir, 2001); (ii) the relationships between these coping strategies and other psychological constructs including emotional intelligence, cognitive self-control, self-monitoring, and empathy (perspective taking, empathetic concern, personal distress, and fantasy); and, (iii) the relationships between these psychological constructs and the experience of psychological distress in adolescents.

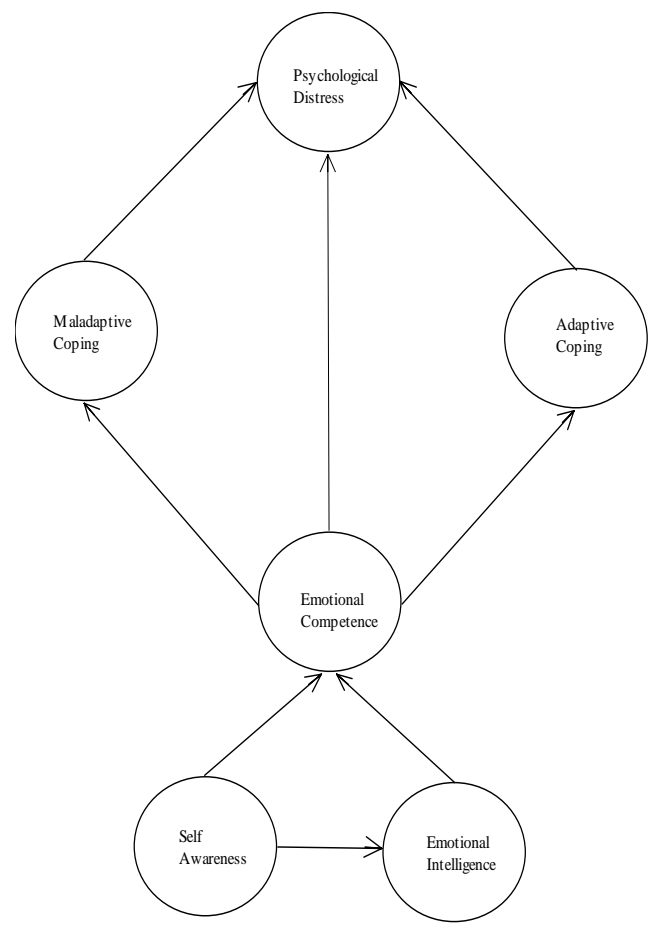

Figure 1: Hypothesised model of relationships between latent constructs.

A number of constructs were derived from the literature and operationalised using established measurement tools. Table 1 details the relationship between the specific measures (manifest) and the hypothesised (latent) constructs. In all, seven scales were used to derive 21 specific measures and these were used to construct six latent factors. The hypothesised paths between the latent constructs are presented in Figure 1. As can be seen, we were broadly interested in testing the hypotheses that; (i) a construct of "emotional competence", comprised of emotional intelligence and self awareness, would have explanatory utility, and that (ii) emotional competence would impact on the coping approaches used which would affect the level of psychological distress.

Partial Least Square Regression (PLS), sometimes called “soft modelling” (Pulos \& Rogness, 1995), was used to evaluate this model. Partial Least Squares PLS can be a powerful method of analysis because it makes minimal demands on measurement scales, sample size, and residual distributions. Although PLS can be used for theory confirmation it is generally recommended in situations where theory or model building, rather than confirmation, are required (Chin, 1997).

The PLS approach combines a number of statistical techniques including, canonical correlation, redundancy analysis, multiple regression, multivariate analysis of variance, and principal components analysis. Part of the strength of this approach is that there are no strong assumptions about the distribution or scale of the data. Thus, PLS copes quite well with non-scalar level measurement and non-normally distributed data. For social scientists a real strength is that PLS approaches cope well with mixed levels of measurement in the same data set (Abdi, 2003).

Another significant advantage of PLS is that sample size can be much smaller than is required in SEM. Chin (1997) recommended, as a rule of thumb, that sample size should be equal to the larger of either: (1) ten times the largest number of formative (i.e., causal) indicators loading on one scale, or (2) ten times the largest number of paths directed at a particular construct in the model.

\section{Method}

\section{Participants}

The sample consisted of 85 students from a local high school in Queensland, Australia. Of the students who provided their demographic data, 44 were females and 18 were males (23 students did not report), and their average age was 16.76 years $(S D=0.47)$. The racial composition of the sample (for those who completed demographic information) was as follows: 57 Caucasian, 2 Aboriginal, and 3 Asian. The majority of the students reported that they lived with both their parents $(82 \%)$, that their fathers worked $(86 \%)$, that their mothers worked (75\%), and 33\% students worked themselves.

\section{Procedure}

Ethics approval for this study was granted by the JCU Research Ethics Committee. 
Table 1 Proposed measurement model: Observed variables loading on latent variable.

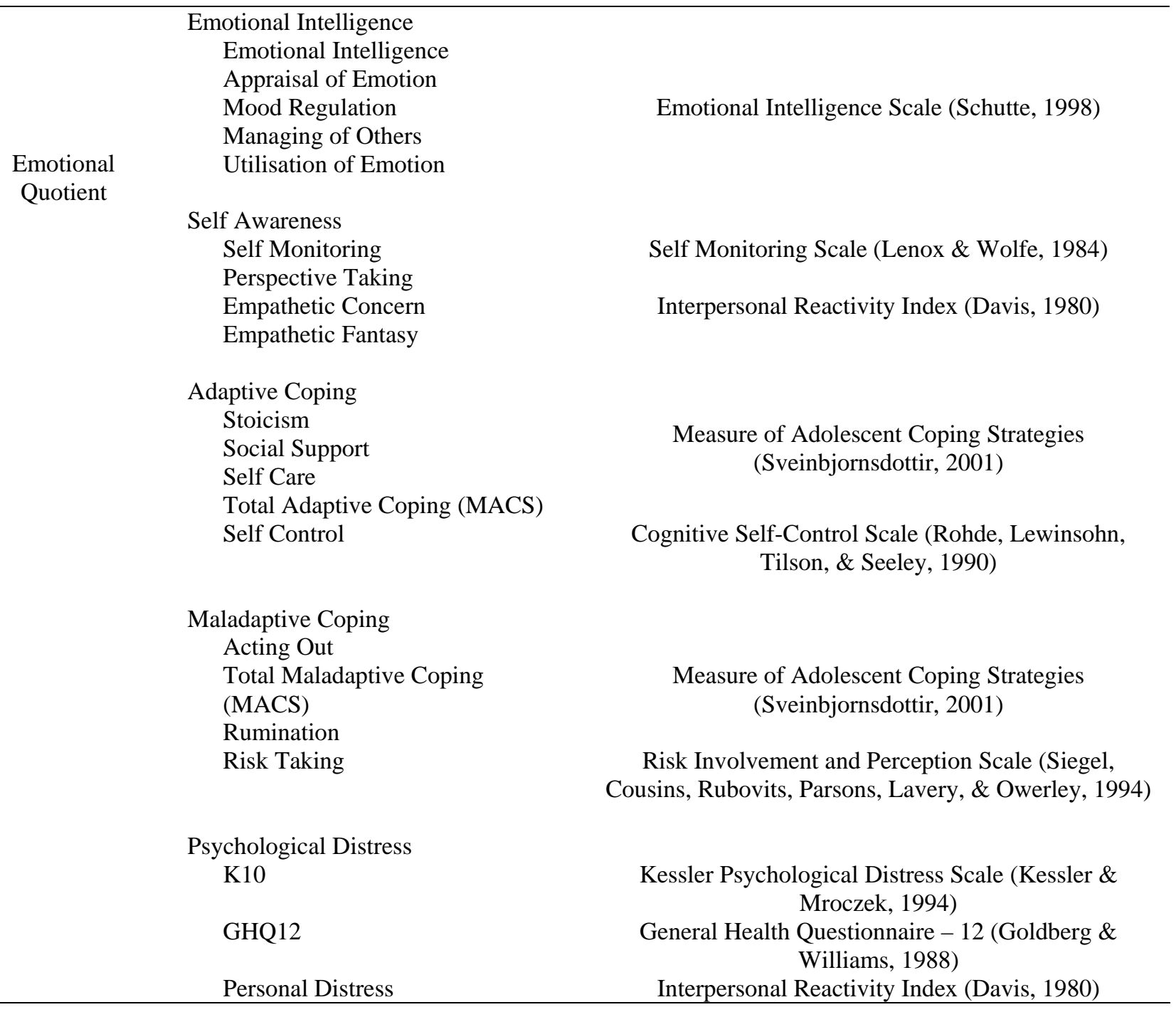


A local high school was approached and the nature and purpose of the research was discussed with the principal who considered that the study was appropriate for the school and agreed to participate. Before commencing the testing sessions, students were briefed about the nature of the study and what participation involved. Students were assembled into group sessions (year 10 \& year 11), where they received information sheets and consent forms.

As the students involved in the study were minors, a written consent was obtained from a primary caregiver prior to their involvement in the study. The students who wished to participate in the study (those who signed and returned the consent forms) received an information sheet and consent form to take home to their parents or guardians. Students and parents' information sheets had standard information concerning the description of the topic of the study, personal nature of the items in the questionnaires, and also stressed that participation in the study was voluntary and anonymous.

Testing took place during school days over two sessions. Students were tested in large groups (e.g., 4050 students). Participants completed a set of 8 questionnaires, as well as a demographic data sheet. The questionnaires took about $30-45$ minutes to complete.

\section{Measures}

Demographic Data Sheet Students answered a brief questionnaire that included information about gender, age, grade, and parents' employment status. In additon, students completed the following measures.

General Health Questionnaire (GHQ-12) The GHQ (Goldberg \& Williams, 1988) is a standard measure of psychological distress used in community settings and non-psychiatric clinical settings, such as primary care or general practice. The scale asks whether the respondent has experienced a particular symptom or behaviour recently, included in the four areas of distress: anxiety and insomnia, depression, social dysfunction, and somatic symptoms. Each item is answered on a 0 to 3 scale, 0 being the highest level of well-being, 3 being the lowest $(0=$ less than usual, $1=$ no more than usual, 2 = rather more than usual, or $3=$ much more than usual). The responses on the questions are summed to make an provide an overall measure of psychological distress or subjective well-being ( 0 to 36). The GHQ-12 is brief, simple, easy to complete, and its application in research settings as a screening tool is well documented (e.g., Hamilton, \& Schweitzer, 2000; O'Connor \& O'Connor, 2003). Use of the GHQ has been validated with adolescents and it has become a popular instrument for use with younger people (Winefield, Goldney, Winefield, \& Tiggemann, 1989).
Kessler Psychological Distress Scale

(K-10) The K-10 (Kessler et al., 2003) is a 10-item self-report questionnaire intended to yield a global measure of 'psychological distress' based on questions about the level of restlessness, anxiety and depressive symptoms. Scores range from 10 to 50. People seen in primary care who score under 20 are likely to be well. People who score 20-24 are likely to have a mild mental disorder; people who score 25-29 have a moderate mental disorder. People who score over 30 are likely to have a severe mental disorder. Administering the $\mathrm{K}-10$ takes about two minutes.

Coping Strategies The Measure of Adolescents Coping Strategies (MACS) (Sveinbjornsdottir, 2001) is a 34-item self-report questionnaire that assesses ways of coping with stressful situations in adolescents. The MACS provides a measure of adaptive coping (Stoicism, 8 items; Social Support, 7 items; and Selfcare, 7 items) and maladaptive coping strategies (Acting-out, 6 items and Rumination, 6 items). Responses are made on a 4-point scale $(0=$ I did not use; 3 = I used almost all the time). Data on validity have been provided by Sveinbjornsdottir (2001).

Emotional Intelligence Participants completed the self-report questionnaire by Schutte et al. (1998), which comprises 33 self-referencing statements and requires subjects to rate the extent they agree or disagree with each statement on a five-point scale ( $1=$ strongly disagree; $5=$ strongly agree). This measure of emotional intelligence assesses to what extent individuals perceive, understand, regulate, and harness emotions adaptively. The total score is determined by the sum of responses over the full set of items, and may range from 33-165 (higher scores indicate higher emotional intelligence). A factor analysis conducted by Petrides and Furnham (2000) and Ciarrochi et al. (2002) revealed the 33-items load into four subscales: emotional appraisal, mood regulation, managing emotions in others, and utilisation of emotions.

Self-Monitoring The revised Self-Monitoring Scale (Lenox \& Wolfe, 1984) provides scores for selfmonitoring and concern for appropriateness on the respondent's self-ratings on a total of 33 items (13 for the Self-Monitoring Scale and 20 for the concern for appropriateness) rating on a six point Likert scale. Only the self-monitoring measure was used in the present study.

Cognitive Self-Control The Cognitive Self-Control Scale (Rohde, Lewinsohn, Tilson, \& Seeley, 1990) was used to assess self-control. It assesses broad skills used to regulate affect and cognitions (e.g., "When I feel that I am too impulsive, I tell myself, 'stop and think before you do anything."'). It contains 21 items scored on a 6point scale (1 to 6$)$. Higher scores reflect higher 
cognitive self-control. Data on reliability and validity have been provided by Rohde et al. (1990).

The Interpersonal Reactivity Index (IRI) The IRI (Davis, 1980) assesses four components of empathy: empathetic perspective taking, empathetic fantasy, empathetic concern, and personal distress. Each subscale consists of 7 items, making a total of 28 items. Respondents rate themselves on each item by using a five-point Likert-type scale $(1=$ does not describe me well, 5 = describes me very well). For each subscale higher scores indicate a greater level of the factor being measured. Davis (1980) and Davis and Franzoi (1991) showed that the internal consistency of the four subscales in the index ranged from .68 to .79. According to validity studies, scores on the subscales were associated with theoretically-related constructs.

Risk Involvement Students completed the Risk Involvement and Perception Scale (RIPS) which is a self-report questionnaire consisting of 19 risk behaviours (Siegel et al., 1994). The RIPS consists of three subscales: frequency of risk involvement, perceived benefits of risk involvement, and perceived risks of risk involvement. These risks range from everyday risks to high-risk behaviours. A total score is obtained for each subscale. Frequency of risk involvement was of interest in this study, so only this subscale was administered.

\section{Results}

The data was analysed using PLSGraph (Chin, 2001), a recent software implementation of the PLS approach. PLS can be considered in two stages; (1) an evaluation of the outer (measurement) model 1, and (2) an evaluation of the inner model2. The results will be reported using this sequence. Standardised data was used in the analysis and, as the number of missing data points was low, missing values were replaced with the sample mean. Significance was evaluated using bootstrapping of 1000 samples of 85 cases which leads to a Critical t-value of 2.33 for $\mathrm{p}<0.01$.

\footnotetext{
${ }^{1}$ The outer model is the relationships between the manifest variables and the hypothesised latent constructs. The analysis essentially needs to answer the question of how well the identified measures predict or construct the latent variables. In PLS this step is akin to Principal Components Analysis (PCA).

${ }^{2}$ The inner model is the relationships between the latent constructs and is the main point of PLS modelling. It involves an evaluation of the pathways between latent constructs using linear regression in which the loadings can be considered as equivalent to Beta weights. In addition, the amount of variance explained in relation to the whole model and specific latent constructs can be used to evaluate the relevance of the modeling.
}

Electronic Journal of Applied Psychology: Emotional Intelligence, Coping and Psychological Distress.3(1):39-

\section{Measurement Model}

The model proposed involved 21 measures (manifest variables) loading on to 6 latent constructs: (1) Emotional Competence, (2) Emotional Intelligence, (3) Self Awareness, (4) Adpative Coping, (5) Maladpative Coping, and (6) Psychological Distress. The latent construct of Emotional Competence was conceptualised as a second-order construct derived from Emotional Intelligence and Self Awareness. The specification of this as a second-order factor followed Chin's (1997; Chin, 2001) suggestion by loading the manifest variables for Emotional Intelligence and Self Awareness on to the Emotional Competence factor. 
Table 2 Discriminant validity of latent constructs.

\begin{tabular}{|c|c|c|c|c|c|c|c|}
\hline & & $\begin{array}{c}\text { Emotional } \\
\text { Quotient }\end{array}$ & $\begin{array}{c}\text { Emotional } \\
\text { Intelligence }\end{array}$ & $\begin{array}{c}\text { Self } \\
\text { Awareness }\end{array}$ & $\begin{array}{c}\text { Adaptive } \\
\text { Coping }\end{array}$ & $\begin{array}{c}\text { Maladaptive } \\
\text { Coping }\end{array}$ & $\begin{array}{c}\text { Psychological } \\
\text { Distress } \\
\end{array}$ \\
\hline \multirow[t]{5}{*}{$\begin{array}{l}\text { Emotional } \\
\text { Intelligence }\end{array}$} & $\begin{array}{l}\text { Emotional } \\
\text { Intelligence }\end{array}$ & 0.95 & 0.99 & 0.53 & 0.56 & -0.01 & -0.08 \\
\hline & $\begin{array}{l}\text { Mood } \\
\text { Regulation } \\
\text { Managing }\end{array}$ & 0.77 & 0.82 & 0.35 & 0.57 & -0.18 & -0.25 \\
\hline & $\begin{array}{l}\text { Others } \\
\text { Emotions }\end{array}$ & 0.84 & 0.87 & 0.48 & 0.58 & 0.02 & 0.02 \\
\hline & $\begin{array}{l}\text { Utilisation } \\
\text { of Emotion }\end{array}$ & 0.73 & 0.79 & 0.35 & 0.38 & 0.07 & -0.08 \\
\hline & $\begin{array}{l}\text { Appraisal of } \\
\text { Emotion }\end{array}$ & 0.68 & 0.68 & 0.48 & 0.27 & 0.12 & 0.03 \\
\hline \multirow[t]{4}{*}{$\begin{array}{l}\text { Self } \\
\text { Awareness }\end{array}$} & $\begin{array}{l}\text { Self } \\
\text { Monitoring }\end{array}$ & 0.63 & 0.50 & 0.75 & 0.36 & -0.01 & -0.05 \\
\hline & $\begin{array}{l}\text { Perspective } \\
\text { Taking }\end{array}$ & 0.56 & 0.36 & 0.82 & 0.41 & -0.02 & -0.08 \\
\hline & $\begin{array}{l}\text { Empathetic } \\
\text { Concern }\end{array}$ & 0.53 & 0.35 & 0.71 & 0.50 & 0.03 & -0.18 \\
\hline & $\begin{array}{l}\text { Empathetic } \\
\text { Fantasy }\end{array}$ & 0.26 & 0.16 & 0.42 & 0.16 & 0.20 & 0.14 \\
\hline \multirow[t]{5}{*}{$\begin{array}{l}\text { Adaptive } \\
\text { Coping }\end{array}$} & Stoicism & 0.39 & 0.31 & 0.42 & 0.77 & -0.16 & -0.28 \\
\hline & $\begin{array}{l}\text { Social } \\
\text { Support }\end{array}$ & 0.53 & 0.52 & 0.37 & 0.80 & 0.00 & -0.19 \\
\hline & Self Care & 0.46 & 0.41 & 0.40 & 0.80 & -0.20 & -0.25 \\
\hline & $\begin{array}{l}\text { Self Control } \\
\text { Total }\end{array}$ & 0.52 & 0.46 & 0.44 & 0.56 & -0.24 & -0.22 \\
\hline & $\begin{array}{l}\text { Adaptive } \\
\text { Coping } \\
\text { (MACS) }\end{array}$ & 0.57 & 0.51 & 0.48 & 0.96 & -0.17 & -0.34 \\
\hline \multirow[t]{3}{*}{$\begin{array}{l}\text { Maladaptive } \\
\text { Coping }\end{array}$} & Acting Out & -0.05 & -0.03 & -0.06 & -0.21 & 0.61 & 0.36 \\
\hline & $\begin{array}{l}\text { Total } \\
\text { Maladaptive } \\
\text { Coping } \\
\text { (MACS) }\end{array}$ & -0.03 & -0.03 & 0.01 & -0.19 & 0.94 & 0.56 \\
\hline & Rumination & 0.00 & -0.02 & 0.07 & -0.13 & .92 & .55 \\
\hline \multirow[t]{3}{*}{$\begin{array}{l}\text { Psychological } \\
\text { Distress }\end{array}$} & K10 & -0.16 & -0.17 & -0.07 & -0.29 & 0.52 & 0.87 \\
\hline & GHQ12 & 0.01 & 0.05 & -0.07 & -0.27 & 0.48 & 0.81 \\
\hline & $\begin{array}{l}\text { Personal } \\
\text { Distress }\end{array}$ & -0.09 & -0.08 & -0.09 & -0.19 & 0.38 & .62 \\
\hline
\end{tabular}

Note. Bold text indicates manifest variable correlations with latent variables that are an order of magnitude beyond other manifest variables. See text for explanation.

The first step to evaluating the measurement model was to examine the discriminant validity of the latent constructs. This was done, following Gefen and Straub (2005), by examining the correlations of the manifest variables with the predicted scores for the latent constructs 3 . Although there are no established thresholds for identifying discriminant validity, Gefen and Straub have suggested that the correlation of a

\footnotetext{
${ }^{3}$ This is something that is automatically generated by PLS-Graph(Chin, 2001) with the appropriate output selected.
}

Electronic Journal of Applied Psychology: Emotional Intelligence, Coping and Psychological Distress.3(1):39- 
manifest variable on its specified latent construct should be at least one order or magnitude above the correlation of the same manifest variable on any other latent construct (pp. 93-94)4. Table 2 presents the correlation matrix of the 21 manifest variables against the 6 latent constructs $^{5}$.

From this it can be seen that the proposed constructs were largely supported. In the main, the correlations between the manifest variables and the relevant latent construct were high (greater than 0.70) and only one manifest variable correlated at the same level with more than one latent variable (Self Control correlated around the same level with the Adaptive Coping, Emotional Intelligence, and Self Awareness constructs). One manifest variable (Risk Taking) had a very weak correlation with its specified latent construct and was weakly correlated with a number of other constructs. Another (Empathetic Fantasy), correlated weakly with the secondary construct Emotional Competence and only moderately with its specified construct of Self Awareness.

Following this analysis, Risk Taking was considered not acceptable and dropped from the analysis of the inner model. Self Control and Empathetic Fantasy were considered as dubious and their performance, along with the other manifest variables, was explored by examining the item weights and loadings of the manifest variables on the latent constructs 6 . This analysis also provided estimates of reliability and Average Variance Explained (AVE) 7 for each of the latent constructs. These results are presented in Table 3.

The loadings of the manifest variables on the latent constructs were generally strong and the reliabilities were high. The AVE for each construct was generally also satisfactory. The manifest variables of Self Control and Empathetic Fantasy had weak, though significant, loadings on their respective latent constructs and were removed. Empathetic Fantasy was removed from both Self Awareness and Emotional Competence. The

\footnotetext{
${ }^{4}$ For example, if a manifest variable correlates 0.70 with the latent construct it could be said to be discriminant if it loads less than 0.60 on any of the other latent constructs.
}

5 The latent variables were derived by PCA of the manifest variables. The correlation of the manifest variables with each other form the basis of the PCA and can be seen in Table 3a.

${ }^{6}$ This is the standard output from PLS-Graph (Chin, 2001) and most other PLS software.

${ }^{7}$ Reliability can be interpreted as internal reliability of the latent construct scale and AVE indicates the amount of variance accounted for in latent construct scores by the combination of manifest variables.

Electronic Journal of Applied Psychology: Emotional Intelligence, Coping and Psychological Distress.3(1):39- removal of the three manifest variables resulted in increased reliability and AVE for Emotional Competence, Self Awareness, Adaptive and Maladpative Coping.

The final measurement model that was used in the analysis of the inner model invloved 18 manifest variables loading on to the six latent constructs. The reliability of these contstructs ranged from 0.82 to 0.92 and the aount of variance explained ranged from $60 \%$ to $74 \%$. Overall, the final measurement model appeared to be quite satisfactory and provided good estimates of the constructs which were in line with the hypothesised relationships.

\section{Inner (Latent) Model}

The evaluation of the structural model of relationships between latent variables is presented in Table 4.

The main thing to notice from Table 2 is that the concepts of Emotional Intelligence and Self Awareness shared a relationship and that Emotional Competence was most strongly related to Emotional Intelligence. Though Self Awareness made a moderate contribution. Interestingly there was no relationship between Emotional Competence and Maladaptive Coping and no direct relationship with Psychological Distress. There was, however, a strong and significant positive relationship between Emotional Competence and Adaptive Coping. Maladaptive Coping had a moderate positive relationship with Psychological Distress whilst Adaptive Coping had a weaker, though still significant, negative relationship with Distress.

Figure 2 summarises these findings in visual form as well as detailing the AVE for the overall model and specific latent constructs. The overall model accounted for a sizeable amount of variance (36\%) and the amount of variance accounted for in Psychological Distress was also high (41\%). The second half of this figure summarises the model with the non-significant pathways removed.

\section{Discussion}

The primary purpose of this study was to explore the relationship between emotional intelligence and ways of coping in adolescents. The model put forward proposed that emotional competence, a compound factor, would be related to coping and distress. Given that a number of measures were used to assess emotional intelligence (or competence), coping strategies and psychological distress, it was important to examine whether these measures were able to be used as predictors of latent variables proposed in a summary model. The evaluation of the measurement model utilising Partial Least Squares (PLS) regression supported the combination of the observed measures into a number of latent factors. In summary, there was support for some aspects of the model proposed. 
Specifically, that a second order factor of emotional competence had some structural and predictive utility and that emotional competence was related to adaptive coping but not to maladaptive coping. Further, coping had a differential relationship to distress, with adaptive coping being related to lower distress scores and maladaptive coping being related with higher distress scores.

The results confirmed that emotional competence was associated with the use of adaptive coping strategies. These findings suggested that adolescents higher in emotional intelligence were more likely to use adaptive coping strategies when faced with stressful situations and that this approach would related to lower levels of psychological distress. These findings are consistent with research by Furnham et al. (2002) and Pelliteri (2002). However, emotional competence had no direct relationship with psychological distress which is contrary to the bulk of previous studies (Ciarrochi, Chan, \& Caputi, 2000; Ciarrochi, Deane, \& Anderson, 2002; Martinez-Pons, 1997; Mayer, Caruso, \& Salovey, 1999; Schutte et al., 1998), although Spence et al. (2004) found that emotional intelligence did not correlate with psychological distress. Maladaptive coping was strongly related to psychological distress but, interestingly 
Table 3 Measurement model estimates.

\begin{tabular}{|c|c|c|c|c|c|c|c|c|c|c|}
\hline & & \multirow[t]{2}{*}{ Weight } & \multirow[t]{2}{*}{ Loading } & \multirow[t]{2}{*}{$\begin{array}{l}\text { Residual } \\
\text { Variance }\end{array}$} & \multirow[t]{2}{*}{ Communality } & \multirow{2}{*}{$\begin{array}{c}\text { Bootstrap Estimates (Loadings) } \\
\qquad \mathrm{t}\end{array}$} & \multicolumn{2}{|c|}{ Construct Estimates } & \multicolumn{2}{|c|}{$\begin{array}{l}\text { Construct Estimate } \\
\text { (Model 2) }\end{array}$} \\
\hline & & & & & & & Reliability & AVE & Reliability & AVE \\
\hline \multirow[t]{9}{*}{ Emotional Quotient } & Emotional Intelligence & 0.22 & 0.95 & 0.09 & 0.91 & $89.89^{* *}$ & \multirow{9}{*}{0.883} & \multirow{9}{*}{0.475} & \multirow{9}{*}{0.896} & \multirow{9}{*}{0.528} \\
\hline & Appraisal of Emotion & 0.14 & 0.68 & 0.54 & 0.46 & $8.76^{* *}$ & & & & \\
\hline & Mood Regulation & 0.19 & 0.77 & 0.41 & 0.59 & $17.16^{* *}$ & & & & \\
\hline & Managing Other's Emotions & 0.20 & 0.84 & 0.29 & 0.71 & $26.20 * *$ & & & & \\
\hline & Utilisation of Emotion & 0.16 & 0.73 & 0.47 & 0.53 & $12.29 * *$ & & & & \\
\hline & Self Monitoring & 0.15 & 0.63 & 0.60 & 0.40 & $5.90^{* *}$ & & & & \\
\hline & Perspective Taking & 0.14 & 0.56 & 0.68 & 0.32 & $6.45^{* *}$ & & & & \\
\hline & Empathetic Concern & 0.14 & 0.53 & 0.72 & 0.28 & $5.32 * *$ & & & & \\
\hline & Empathetic Fantasy & 0.06 & 0.26 & 0.93 & 0.07 & $1.96^{*}$ & & & & \\
\hline \multirow[t]{5}{*}{$\begin{array}{l}\text { Emotional } \\
\text { Intelligence }\end{array}$} & Emotional Intelligence & 0.28 & 0.99 & 0.01 & 0.99 & $296.94 * *$ & \multirow{5}{*}{0.921} & \multirow{5}{*}{0.703} & \multirow{5}{*}{-} & \multirow{5}{*}{-} \\
\hline & Mood Regulation & 0.23 & 0.82 & 0.32 & 0.68 & $23.1825^{* *}$ & & & & \\
\hline & Managing Others Emotions & 0.25 & 0.87 & 0.24 & 0.76 & $34.68 * *$ & & & & \\
\hline & Utilisation of Emotions & 0.22 & 0.79 & 0.38 & 0.62 & $14.47 * *$ & & & & \\
\hline & Appraisal of Emotion & 0.20 & 0.68 & 0.53 & 0.47 & $10.12^{* *}$ & & & & \\
\hline \multirow[t]{4}{*}{ Self Awareness } & Self Monitoring & 0.44 & 0.75 & 0.43 & 0.57 & $11.77^{* *}$ & \multirow{4}{*}{0.777} & \multirow{4}{*}{0.476} & \multirow{4}{*}{0.815} & \multirow{4}{*}{0.596} \\
\hline & Perspective Taking & 0.40 & 0.82 & 0.33 & 0.67 & $16.30^{* *}$ & & & & \\
\hline & Empathetic Concern & 0.37 & 0.71 & 0.50 & 0.50 & $7.25 * *$ & & & & \\
\hline & Empathetic Fantasy & 0.18 & 0.42 & 0.82 & 0.18 & $2.28 * *$ & & & & \\
\hline \multirow[t]{5}{*}{ Adaptive Coping } & Stoicism & 0.22 & 0.77 & 0.40 & 0.60 & $11.68^{* *}$ & \multirow{5}{*}{0.887} & & & \\
\hline & Social Support & 0.26 & 0.80 & 0.36 & 0.64 & $16.21^{* *}$ & & \multirow{4}{*}{0.573} & \multirow{4}{*}{ - } & \multirow{4}{*}{ - } \\
\hline & Self Care & 0.24 & 0.80 & 0.36 & 0.64 & $17.89 * *$ & & & & \\
\hline & Self Control & 0.26 & 0.56 & 0.69 & 0.31 & $4.44 * *$ & & & & \\
\hline & $\begin{array}{l}\text { Total Adaptive Coping } \\
\text { (MACS) }\end{array}$ & 0.30 & 0.96 & 0.07 & 0.93 & $55.40 * *$ & & & & \\
\hline \multirow[t]{3}{*}{$\begin{array}{l}\text { Maladaptive } \\
\text { Coping }\end{array}$} & Acting Out & 1.10 & 0.61 & 0.63 & 0.37 & $3.54 * *$ & & & & \\
\hline & $\begin{array}{c}\text { Total Maladaptive Coping } \\
\text { (MACS) }\end{array}$ & -1.07 & 0.94 & 0.12 & 0.88 & $10.88^{* *}$ & 0.785 & 0.528 & 0.883 & 0.723 \\
\hline & $\begin{array}{l}\text { Rumination } \\
\text { Risk Taking }\end{array}$ & 1.50 & 0.92 & 0.16 & $\begin{array}{l}0.84 \\
0.03\end{array}$ & $\begin{array}{c}10.26 * * \\
0.67\end{array}$ & & & & \\
\hline Psychological & K10 & -0.22 & 0.17 & 0.97 & 0.03 & $0.6 /$ & & & & \\
\hline Distress & & 0.40 & 0.1 & 0.24 & 0.10 & $1540 * *$ & 0.817 & 0.603 & - & - \\
\hline & $\begin{array}{l}\text { GHQ12 } \\
\text { Personal Distress }\end{array}$ & $\begin{array}{l}0.45 \\
0.35\end{array}$ & $\begin{array}{l}0.81 \\
0.62\end{array}$ & $\begin{array}{l}0.34 \\
0.61\end{array}$ & $\begin{array}{l}0.66 \\
0.39\end{array}$ & $6.38 * *$ & & & & \\
\hline
\end{tabular}

${ }^{* *} \mathrm{p}<0.01$ (Critical t-value $=2.33$, Bootstrap $=500$ )

${ }^{*} \mathrm{p}<0.05$ (Critical t-value $=1.66$, Bootstrap $\left.=500\right)$

Table 3a Inter-item correlations.

Emotional Intelligence 


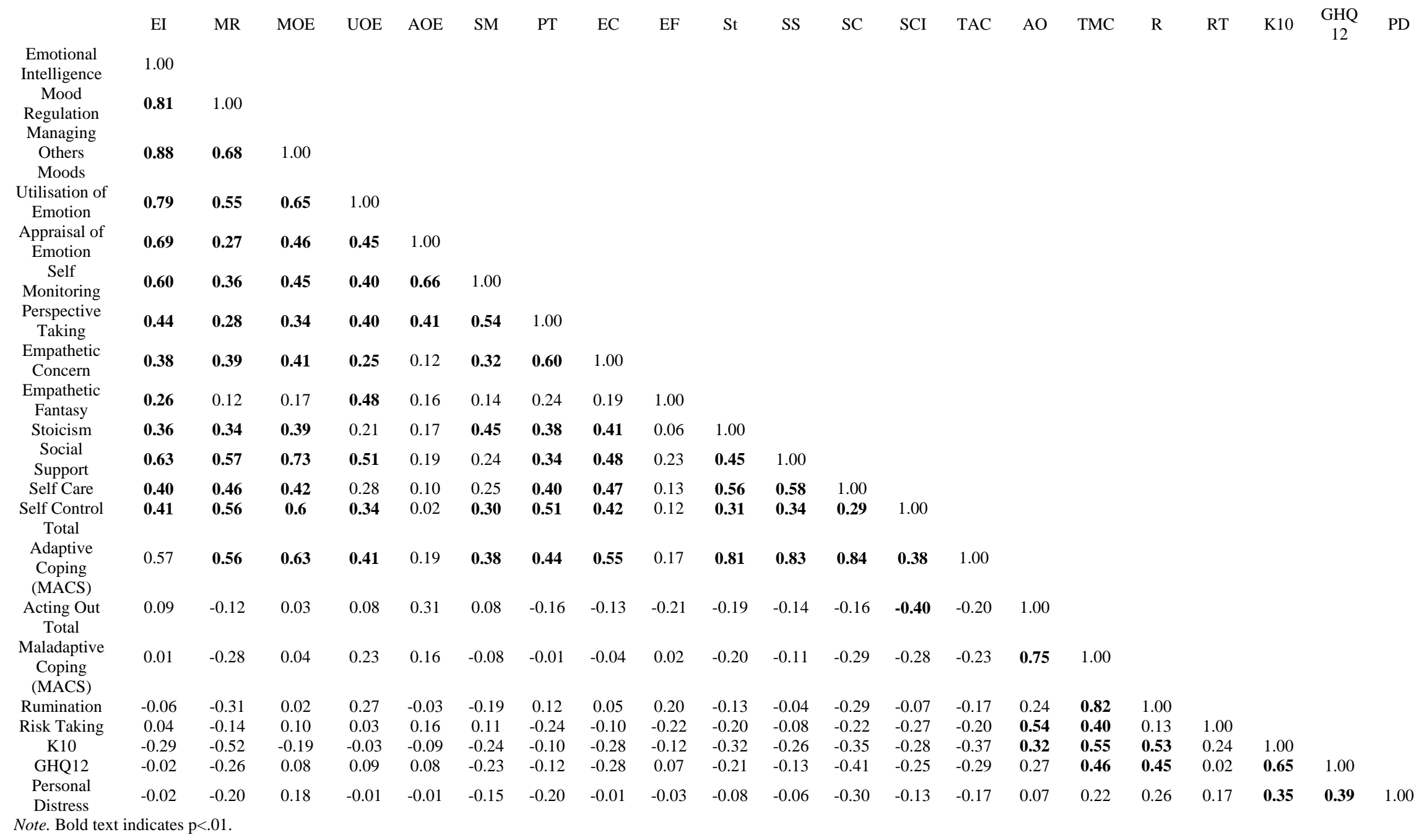


Table 4: Path coefficients for Hypothesised Inner Model

\begin{tabular}{|c|c|c|c|c|}
\hline & & Path Coefficient & S.E. & $\mathrm{t}$ \\
\hline \multirow[t]{5}{*}{ Emotional Quotient } & Emotional Intelligence & 0.76 & 0.05 & $15.29 * *$ \\
\hline & Self Awareness & 0.36 & 0.04 & $8.55^{* *}$ \\
\hline & Adaptive Coping & 0.68 & 0.08 & $8.15^{* *}$ \\
\hline & Maladaptive Coping & 0.01 & 0.14 & 0.06 \\
\hline & Psychological Distress & 0.09 & 0.14 & 0.68 \\
\hline Awareness & Emotional Intelligence & 0.53 & 0.08 & $6.13^{* *}$ \\
\hline \multirow[t]{2}{*}{ Psychological Distress } & Adaptive Coping & -0.30 & 0.12 & $2.37 * *$ \\
\hline & Maladaptive Coping & 0.55 & 0.08 & $6.26 * *$ \\
\hline
\end{tabular}

${ }^{* *} \mathrm{p}<0.01$ (critical t-value $=2.33$, bootstrapt $=500$ ) 
there was no relationship of emotional competence to maladaptive coping which is, again, at odds with previous research (Brackett \& Mayer, 2003; Brackett, Mayer, \& Warner, 2004; Trinidad, 2002).

Having said this, the limitations of the present study require that the results need to be considered preliminary and speculative. Although PLS copes well with small sample sizes, and particularly provides stable estimates of path coefficients (Chin, 1995), power with the current sample size is necessarily reduced and difficult to estimate. In addition, the concept of emotional competence is new in this model and really requires more extensive evaluation, not withstanding the strong support for the concept in our modeling. We also did not take account of gender in this study and, given that there are known gender differences in relation to coping, future studies should take account of this. Finally, our data was generated through a cross-sectional design yet modeling of causal relationships requires a longitudinal or mixed design. Certainly, our modeling does not allow us to any more than speculate about the directions of influence between the latent constructs .
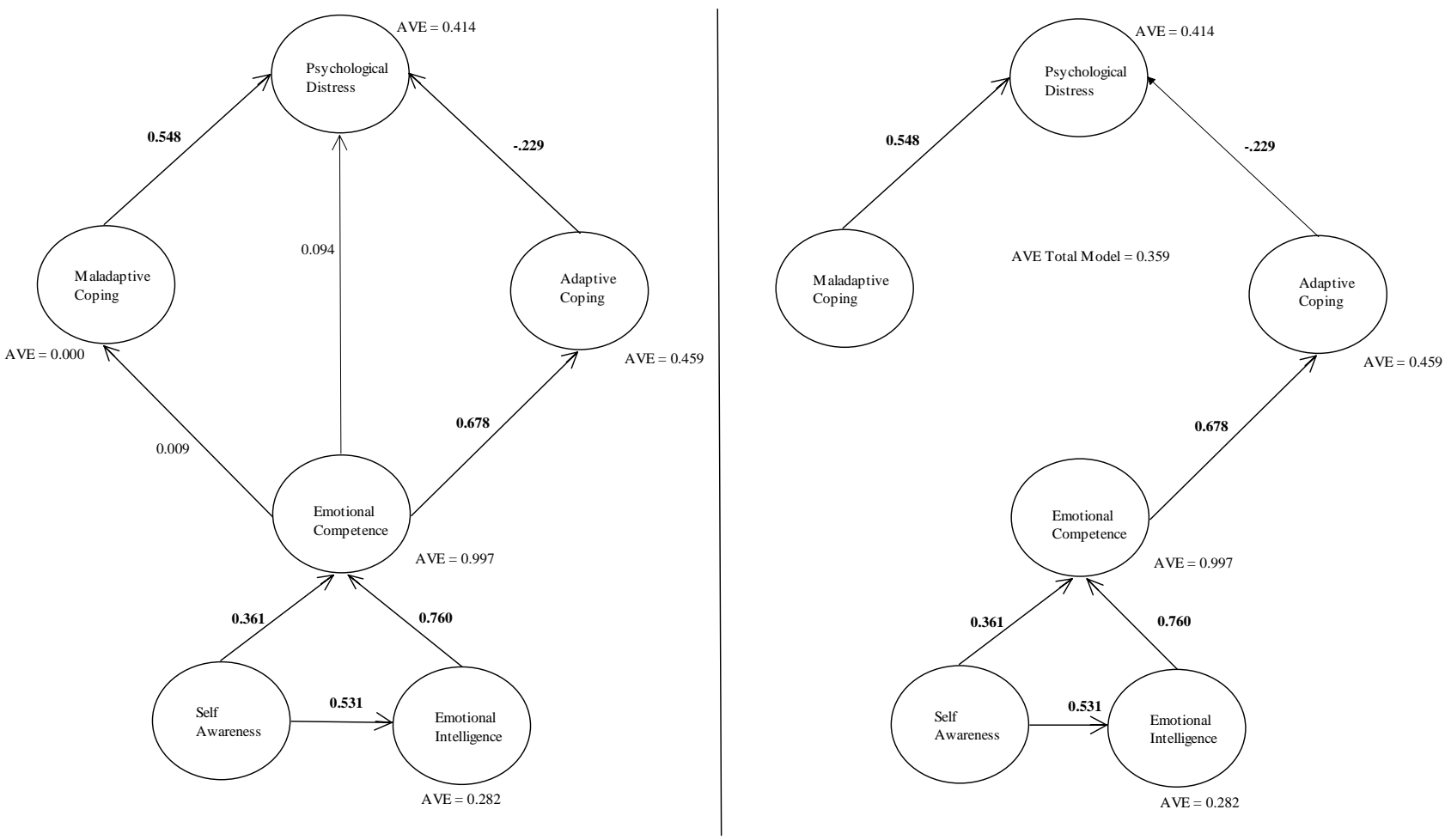

A: Inner Model with All Paths Shown

Figure 2: Path Estimates for Inner Model 
Taken together, though, these findings suggested that emotional competence is relevant to promoting adaptive coping in adolescents but has only a minimal relationship to the experience of psychological distress. The biggest indicator of psychological distress was the use of maladpative coping strategies and these were not influenced by emotional competence. Therefore, attempts to promote emotional competence may improve adaptive coping but our modelling did not support a link between emotional competence and distress. The biggest impact appears to require changing the use of malapative coping strategies. Future modeling needs to look at which factors are related to maladaptive coping so that strategies can be developed.

We would also urge others to explore the use of PLS modeling in this context. Our experience was that this approach to modeling is very useful in situations where no strong models currently exist as it assists in the development of models of relationships rather than the more usual confirmation involved in Structural Equation Modeling. This promotes an exploratory approach to the data and to the structures which promotes theory building.

1 The outer model is the relationships between the manifest variables and the hypothesised latent constructs. The analysis essentially needs to answer the question of how well the identified measures predict or construct the latent variables. In PLS this step is akin to Principal Components Analysis (PCA).

2 The inner model is the relationships between the latent constructs and is the main point of PLS modelling. It involves an evaluation of the pathways between latent constructs using linear regression in which the loadings can be considered as equivalent to Beta. In addition, the amount of variance explained in relation to the whole model and specific latent constructs can be used to evaluate the relevance of the modeling.

3 This is something that is automatically generated by PLSGraph(Chin, 2001) with the appropriate output selected.

4 For example, if a manifest variable correlates 0.70 with the latent construct it could be said to be discriminant if it loads less than 0.60 on any of the other latent constructs.

5 This is the standard output from PLS-Graph (Chin, 2001) and most other PLS software.

6 Reliability can be interpreted as internal reliability of the latent construct scale and AVE indicates the amount of variance accounted for in latent construct scores by the combination of manifest variables.

\section{References}

Abdi, H. (2003). Partial Least Squares (PLS) Regression. In M. Lewis-Beck, A. Bryman \& T.
Futing (Eds.), Encyclopedia of Social Sciences Research Methods. Thousand Oaks (CA): Sage.

Bar-On, R. (1997). EQ-i: Bar-On emotional quotient inventory: A measure of emotional intelligence: Technical manual. Toronto, ON: Multi-Health Systems Inc.

Barkley, R. (1997). Behavioral inhibition, sustained attention, and executive functions: Constructing a unifying theory of ADHD. Psychological Bulletin, 121, 65-94.

Brackett, M.A.., \& Mayer, J.D. (2003). Convergent, Discriminant, and Incremental Validity of Competing Measures of Emotional Intelligence. Personality and Social Psychology Bulletin, 29, 1147-1158.

Brackett, M., Mayer, J., \& Warner R. (2004). Emotional intelligence and its relation to everyday behaviour. Personality and Individual Differences, 36, 1387-1402.

Chin, W.W. (1995). Partial Least Squares is to LISREL as principal components analysis is to common factor analysis. Technology Studies, 2, 315-319.

Chin, W.W. (1997). Overview of the PLS Method: University of Houston. http://discnt.cba.uh.edu/chin/PLSINTRO.HTM

Chin, W.W. (2001). PLS-Graph User's Guide: Soft Modeling Inc.

Ciarrochi, J.I., Deane, F.P., Anderson S. (2002). Emotional intelligence moderates the relationship between stress and mental health. Personality and Individual Differences, 32, 197-209.

Ciarrochi, J.V., Chan, A.Y.C., Caputi, P. (2000). A critical evaluation of the emotional intelligence construct. Personality and Individual Differences, 28, 539-561.

Ciarrochi, J., Chan, A.Y.C., \& Bajgar, J. (2001). Measuring emotional intelligence in adolescents. Personality and Individual Differences. 31, 11051119

Ciarrochi, J., Chan, A., Caputi, P., \& Roberts, R. (2001). Measuring emotional intelligence. In J. Ciarrochi, J.P Forgas, \& J.D Mayer (Eds.), Emotional Intelligence in everyday life: A scientific inquiry. Philadelphia, PA: Psychology Press.

Compas, B.E. (1987). Coping with stress during childhood and adolescence. Psychological Bulletin, 101, 393-403.

Compas, B.E., Connor-Smith, J. J., Saltzman, H., Thomsen, A.H., \& Wadsworth, M.E. (2001). Coping with stress during childhood and adolescence: Problems, progress, and potential theory development. Psychological Bulletin, 127, 87-127.

Davis, M.H. (1980). A multidimensional approach to individual differences in empathy, JSAS Catalog of Selected Documents in Psychology, 10, 85.

Davis, M., \& Franzoi, S. (1991). Stability and change in adolescent self-consciousness and empathy. Journal of Research in Personality, 25, 70-87. 
Furnham, A., Petrides, K., \& Spencer-Bowdage, S. (2002). The effects of different types of social desirability on the identification of repressors. Personality and Individual Differences, 33, 119-130.

Gefen, D., \& Straub, D. (2005). A practical guide to factorial validity using PLS-Graph: Tutorial and annotated example. Communication of the Association for Information Systems, 16, 91-109.

Goldberg, D., and Williams, P.A.. (1988). Users Guide to General Health Questionnaire. NFER-Nelson.

Goleman, D. (1995). Emotional Intelligence. New York: Bantam Books.

Hamilton, T., \& Schweitzer, R. (2000). The cost of being perfect: perfectionism and suicide ideation in university students. Australian and New Zealand Journal of Psychiatry., 34, 829-835.

Jordan, P.J., Troth, A.C. (2002). Emotional intelligence and conflict resolution: Implications for human resource development. Advances in Developing Human Resources, 4, 62-79.

Kessler, R., Barker, P., Colpe, L., Epstein, J., Gfroerer, J., Hiripi, E., et al. (2003). Screening for serious mental illness in the general population. Archives of General Psychiatry, 60, 184-189.

Lazarus, R. S., \& Folkman, S. (1984). Stress, appraisal, and coping. New York: Springer.

Lennox, R.D., \& Wolfe, R.N. (1984). Revision of the Self-Monitoring Scale. Journal of Personality and Social Psychology, 46, 1349-1364.

Mayer, J.D., \& Salovey, P. (1997). What is Emotional Intelligence? In P. Salovey \& D.J. Sluyter (Ed.), Emotional Development and Emotional Intelligence. New York: Basic Books.

Mayer, J.D., Caruso, D.R., \& Salovey, P. (1999). Emotional intelligence meets traditional standards for an intelligence. Intelligence, 27, 267-298.

Moulds, J.D. (2003). Stress manifestation in high school students: An Australian Sample. Psychology in the Schools, 40, 391-402.

Mullis, R. L., \& Chapman, P. (2000). Age, gender and self esteem differences in adolescent coping styles. Journal of Social Psychology, 140, 252-256.

O’Connor, R.C., \& O’Connor, D.B. (2003). Predicting hopelessness and psychological distress: The role of perfectionism and coping. Journal of Counselling Psychology, 50, 362-372.

Pelliteri, J. (2002). The relationship between emotional intelligence and ego defense mechanisms. Journal of Psychology, 136, 182-194.

Petrides, K., \& Furnham, A. (2000). On the dimensional structure of emotional intelligence. Personality and Individual Differences, 29, 313-320.

Printz, B.L., Shermis, M.D., \& Webb, P. M. (1999). Stress-buffering factors related to adolescent coping: a path analysis. Adolescence, 34, 715-34.
Pulos, S., \& Rogness, N. (1995). Soft modelling and special education. Remedial and Special Education, 16, 184-192.

Recklitis, C.J., \& Noam, G.G. (1999). Clinical and development perspectives on adolescent coping. Child Psychiatry and Human Development, 30, 87101.

Rigby, K., \& Cox, I. (1996). The contribution of bullying at school and low self-esteem to acts of delinquency among Australian teenagers. Personality and Individual Differences, 21, 609-612.

Rohde, P., Lewinsohn, P.M., Tilson, M., \& Seeley, J.R. (1990). Dimensionality of coping and its relation to depression. Journal of Personality and Social Psychology, 58, 499-511.

Rutter, M., \& Smith, D. (1995). Psychosocial disorders in young people: time trends and their causes. London: J Wiley \& Sons.

Salovey, P., \& Mayer, J.D. (1990). Emotional intelligence. Imagination, Cognition and Personality, $9,185-211$

Schutte, N.S., Malouff, J.M., Hall, L.E., Haggerty, D. J., Cooper, J.T., Golden, C.J., \& Dornheim, L. (1998). Development and validation of a measure of emotional intelligence. Personality and individual differences, 25, 167-177.

Seiffge-Krenke, I., \& Klessinger, N. (2000). Long-term effects of avoidant coping on adolescents' depressive symptoms. Journal of Youth and Adolescence, 29, 617-630.

Siegel, A. W., Cousins, J.H., Rubovits, P., Parsons, J. T., Lavery, B., \& Crowley, C.L. (1994). Adolescents' perceptions of the benefits and risks of their own risk taking. Journal of Emotional and Behavioural Disorders, 2, 89-98.

Spence, G., Oades, L.G., \& Caputi, P. (2004). Trait emotional intelligence and goal self-integration: important predictors of emotional well-being? Personality and Individual Differences, 37, 449-461.

Strayhorn, J. (2002). Self-control: theory and research. Journal of the American Academy of Child and Adolescent Psychiaty, 41, 7-16.

Sveinbjornsdottir, S. (2001). The assessment of adolescent coping: development of a new measure. Greenwood.

Swiatek, M. (1995). An Empirical Investigation of the Social Coping Strategies Used by Gifted Adolescents. Gifted Child Quarterly, 39, 154-61

Swiatek, M. (2001). Social Coping Among Gifted High School Students and its Relationship to Self-Concept. Journal of Youth and Adolescence. 30, 19-39.

Taylor, G. (2001). Low emotional intelligence and mental illness, In J. Ciarrochi, J.P. Forgas, \& J.D Mayer. (Eds) (2001). Emotional intelligence in everyday life: A scientific inquiry. pp.67-81. Philadelphia: Taylor \& Francis

Tolor, A.., \& Fehon, D. (1987). Coping with stress: A study of male adolescents' coping strategies as 
related to adjustment. Journal of Adolescent Research, 2, 33-42.

Trinidad, D. R., \& Johnson, C. A.. (2001). The association between emotional intelligence and early adolescent tobacco and alcohol use. Personality and Individual Differences, 32, 95-105.

Trinidad, D.R., Unger, J.B., Chou, C.P., Azen, S.P., \& Johnson, C.A. (2004). Emotional intelligence and smoking risk factors in adolescents: Interactions on smoking intentions. Journal of Adolescent Health, 34, 46-55.

Winefield, H.R., Goldney, R.D., Winefield, A.H., \& Tiggemann, M. (1989). The General Health Questionnaire: Reliability and validity for Australian youth. Australian and New Zealand Journal of Psychiatry, 23, 53-58

Correspondence to: Alistair Campbell

(Alistair.Campbell@jcu.edu.au)

School of Psychology

James Cook University, Townsville, Australia 